Portrait of Ms. Diaz: Empirical study of patient journey mapping instruction for medical professional students

\author{
Hannah Park \\ University of Kansas, Lawrence, KS, USA \\ Helen Monkman \\ University of Victoria, Victoria, BC, Canada \\ Allison Wenger \\ University of Kansas, Lawrence, KS, USA \\ Blake Lesselroth \\ University of Oklahoma-Tulsa, Tulsa, OK, USA
}

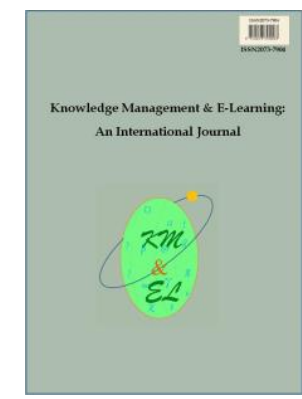

Knowledge Management \& E-Learning: An International Journal (KM\&EL) ISSN 2073-7904

Recommended citation:

Park, H., Monkman, H., Wenger, A., \& Lesselroth, B. (2020). Portrait of Ms. Diaz: Empirical study of patient journey mapping instruction for medical professional students. Knowledge Management \& E-Learning, 12(4), 469-487. https://doi.org/10.34105/j.kmel.2020.12.026 


\title{
Portrait of Ms. Diaz: Empirical study of patient journey mapping instruction for medical professional students
}

\author{
Hannah Park* \\ The Department of Design \\ School of Architecture and Design \\ University of Kansas, Lawrence, KS, USA \\ E-mail: design_park@ku.edu

\section{Helen Monkman} \\ Health Information Science \\ University of Victoria, Victoria, BC, Canada \\ E-mail: monkman@uvic.ca
}

\author{
Allison Wenger \\ University of Kansas, Lawrence, KS, USA \\ E-mail: allisonjwenger@gmail.com
}

\section{Blake Lesselroth}

Department of Medical Informatics

School of Community Medicine

University of Oklahoma-Tulsa, Tulsa, OK, USA

E-mail: blake-lesselroth@ouhsc.edu

*Corresponding author

\begin{abstract}
An interdisciplinary team of educators from medicine, design, and informatics piloted an online journey map (JM) exercise targeting 48 medical students and physicians assistants students. The JM exercise was designed to teach about patient empathy skills, person-centred care, and the socio-ecologic determinants of health. Prior to the exercise, the students were given a sample patient archetype introducing Ms. Diaz, a person with diabetes visiting a virtual clinic. Students worked in small groups to create a JM from Ms. Diaz' perspective about, and experiences with, a telemedicine clinic. Our preliminary qualitative analysis of the JMs from the exercise showed that learners were able to create JMs that included all key sections including process phases, user perceptions, pain points, and design opportunities. Almost half of the responses focused upon socio-cultural and socio-technical issues as opposed to strictly clinical concerns. We believe this pilot shows the potential for journey maps to be used in health professional education to empathize with patients, identify societal problems in healthcare delivery, and design responsive solutions. Furthermore, the virtual classroom format highlights the scalability and extensibility of this strategy to a broad range of educational goals.
\end{abstract}

Keywords: Journey map; People-centred design; Person-centred care; 
Empathy education; Medical education

Biographical notes: Hannah Park, MDes is an Assistant Professor in the School of Architecture and Design, University of Kansas. Her research interests include the role of design thinking in healthcare, which involves electronic health records, consumer health information, medical education, and mental healthcare. She has facilitated numerous community-engaged design scholarship projects with her students, which were funded by a wide range of organizations, including Frost Bank, Make A Wish Foundation, Audubon National Society, SRVS Disability Support Memphis, and Hill's Pet Nutrition, Colgate-Palmolive. Her research has been presented internationally, including AIGA, CAA, Cumulus, E\&PDE, RASC, SXSW EDU, and TEDx.

Dr. Helen Monkman is an Assistant Professor in the School of Health Information Science at the University of Victoria. Her mission is to improve consumer health information systems by making them easier for people to use and the information therein easier to understand. Her work seeks to empower people and help them make better health decisions as well as have better conversations with their health care providers. Her research interests include human factors, user experience, usability, eHealth literacy, digital health literacy, information visualization, and how these factors impact the use and understandability of consumer health information systems.

Allison Wenger is a second-year undergraduate student majoring in Biochemistry at the University of Kansas. She is currently working with Professor Hannah Park and Professor Blake Lesselroth as a research assistant.

Dr. Blake Lesselroth is an Associate Professor of Internal Medicine and ViceChair of Medical Informatics at the University of Oklahoma-Tulsa School of Community Medicine. He manages a portfolio consisting of implementation science research, medical informatics and health-systems science education, and IT service delivery. His areas of expertise include medical decisionmaking, healthcare quality improvement, human-computer interactions, user experience and usability research methods, mixed methods research, and implementation and dissemination science. Presently, he is engaged in research and publishing on topics related to computerized decision support, humancomputer interactions, user experience methods, telemedicine, and patient safety.

\section{Background}

\subsection{Pivoting to person-centred care}

Person-centred care is a set of care quality principles that gained prominence through landmark publications including the Institute of Medicine's Crossing the Quality Chasm and the Institute of Healthcare Improvement's Triple Aim (Berwick, Nolan, \& Whittington, 2008; Corrigan, 2005). Person-centred care aligns health delivery with the values, expectations, and context of the person and is achieved when health professionals involve patients in healthcare conversations and decision-making (Constand, MacDermid, Dal Bello-Haas, \& Law, 2014; Mead \& Bower, 2000). Person-centred care is also a paradigm of health systems delivery that requires the entire care team to empathize with 
the patient; it uses patients' knowledge and experiences to improve the individual experience of care (Bechtel \& Ness, 2010; Davis et al., 2004).

McWhinney (1989) wrote that person-centred care requires the practitioner to "enter the patient's world, to see the illness through the patient's eyes" (p.34) (McWhinney, 1989). If the healthcare industry is to successfully pivot from a practitioner or payer-centred model to one that is person-centred, health professional training programs must integrate empathy education in their curricula to cultivate a shared understanding among stakeholders and "bake" consumer engagement into systems design (Davis, Schoenbaum, \& Audet, 2005). Presently, most medical or health professional schools include educational objectives for systems-based practice and include health systems science topics such as population medicine, medical informatics, and quality improvement (Skochelak, 2016). However, students rarely receive hands-on instruction in systems engineering or person-centred design. Stated simply, health professional students learn about the interconnectedness of systems, the importance of interdisciplinary collaboration, and the need for patient empathy, but they are rarely equipped with the practical tools to conduct user empathy research or participate on interprofessional design teams (Halton \& Cartwright, 2018). This gap is particularly germane because the current care ecosystem is becoming increasingly digital. The rapid advancement of telemedicine, tele monitoring, and direct-to-consumer product marketing threatens to widen an already significant access-to-care gap unless we focus commensurate resources teaching person-centred care principles including empathy towards the people using this technology.

\subsection{Person-centred design and design thinking methods}

Interprofessional collaborative practice is a critical ingredient in the performance of highreliability organizations and a foundational component of health systems science (Skochelak, 2016). In this spirit, we see an educational opportunity to "borrow" and adapt instructional techniques and best-practices from other industries. User Interface/User Experience (UI/UX) design pedagogies include design thinking approaches intended to cultivate empathy with users of technology (Lesselroth et al., 2020). Design thinking is a methodology for creative problem-finding and solving that emphasizes empathy and a people-centred approach (Park et al., 2021). Similar to the Plan-Do-Study-Act cycles used by healthcare quality practitioners, designers use an iterative, person-centred design cycle to understand user needs, ideate design solutions, converge upon prototypes, and test prototypes with users (Hartson \& Pyla, 2012; Soegaard, 2018). During the "understand" phase, experts use a range of ethnographic techniques to collect, organize, and describe user attributes, values, attitudes, and needs. Ethnographic techniques can include interviews, focus groups, direct observations, and artifact analysis. Documents generated during the understand phase can include user personas, empathy maps, workflows, and journey maps (Martin \& Hanington, 2012; Kumar, 2012).

\subsection{Problem statement: Using journey mapping to teach about health-related social needs}

To meet national accreditation requirements for allopathic medical schools, the University of Oklahoma-Tulsa School of Community Medicine (OU-TU) curriculum includes content addressing health-related social needs and community stewardship (Englander et al., 2013; Englander et al., 2017). These domains and competencies are foundational to person-centred care, but can be difficult to teach using participatory 
methods (Table 1). In our program, we needed to explain how socio-ecologic determinants of health affect patient outcomes and the equitable distribution of health within a community. At the same time, we needed a set of immersive activities and measurement strategies to equip learners with skills that build empathy and guide systems-based improvement. Therefore, faculty at OU-TU partnered with faculty at the School of Architecture and Design, University of Kansas (KU) and faculty at the School of Health Information Science at the University of Victoria (UVic) to develop and pilot a day-long workshop dealing with socio-ecologic determinants of health. During the skills training section, we asked students to journey map (JM) a hypothetical patient healthcare encounter.

Table 1

Clinical competency domains and associated education program objectives for our allopathic medical school and physicians assistant school

\begin{tabular}{|c|c|}
\hline Competency Domain & Educational Program Objective \\
\hline Medical Knowledge & $\begin{array}{l}\text { - Students demonstrate knowledge of basic scientific knowledge } \\
\text { - } \\
\text { - Students understand the pathogenesis and manifestation of disease } \\
\text { Students understand the utility, mechanisms, and effects of } \\
\text { commonly used drugs } \\
\text { - Students know the physical, emotional, and social aspects of human } \\
\text { development }\end{array}$ \\
\hline Patient Care* & $\begin{array}{l}\text { - } \quad \text { Students can collect a medical history and perform a physical exam } \\
\text { - } \\
\text { - }\end{array}$ \\
\hline Communication & $\begin{array}{l}\text { - Students use effective listening and communication techniques with } \\
\text { patients } \\
\text { - } \quad \text { Students deliver clear and accurate oral medical presentations } \\
\text { - Students document accurate and context-specific information about } \\
\text { encounters }\end{array}$ \\
\hline Professionalism & $\begin{array}{l}\text { - Students demonstrate integrity, respect, reliability, and } \\
\text { accountability }\end{array}$ \\
\hline
\end{tabular}

Note. * Domains and objectives addressed with this project

\subsection{Aims and goals for this manuscript}

In this paper, we provide a case study of our journey mapping exercise with health professional students and the analytic strategy we used to evaluate student deliverables. We furnished students with a telemedicine case, asking them to explore how technology could inadvertently increase access-to-care barriers among vulnerable or marginalized populations. Our aim with this manuscript is to illustrate how journey mapping can be 
used in medical education as a constructivist approach to build competencies in patient care, professionalism, and systems-based practice. We have outlined several educational goals for the reader. After reviewing this manuscript, the reader should be able to:

1) use journey mapping as an engagement strategy to teach about health-related social needs;

2) facilitate journey mapping in a virtual classroom using multiple cloud-based software platforms;

3) explain how journey mapping provides a useful tool to understand the patient experience; and

4) analyse journey maps to measure the attitudes and skills of learners in the health professions.

This manuscript should be of interest to healthcare educators, design educators, healthcare systems designers, health-systems scientists, systems engineers, visual communication designers, informaticians, and graduate program curriculum directors.

\section{Methods}

\subsection{Theoretical framework}

Our work integrates two conceptual models; one relates to the methodological framework of design thinking and the other relates to the content domain of person-centred care (Fig 1). The Design Thinking Process diagrammed in Fig. 1 is a sequential, yet iterative "wheel" for designing products or experiences (Hartson \& Pyla, 2012; Tjendra, 2014). The lifecycle is composed of sub-activities: (1) empathize with the user; (2) define the need; (3) design solutions; and (4) evaluate the design. The wheel should handle feedback at every phase; new insights may require the design team to iterate several times during a phase or revisit an earlier phase. The "empathize with the user" phase includes user experience techniques for data elicitation including user interviews and observations. It also includes deliverables that offer new insights about users and that foster a shared understanding among stakeholders.

The second conceptual model, the Person-Centred Care model (sometimes called "Patient-Centred Care"), has been an evolving concept in the medical literature for over 50 years (Santana et al., 2018). Many different models have been used to describe the components and function of person-centred care (Tanenbaum, 2015). We adapted a model developed by Scholl and colleagues that represents the nested and inter-related nature of micro and macro-systems (Scholl, Zill, Härter, \& Dirmaier, 2014a, 2014b). Person-centred care can be conceptualized at the individual (i.e., micro) level and at the systems (i.e., macro) level. The micro level refers to dynamics inside and around the patient-clinician encounter (Scholl et al., 2014a, 2014b). The macro level considers services tailored to groups of patients and the design of health systems to engage and empower patients (Santana et al., 2018).

The Design Thinking Process strongly emphasizes the importance of eliciting requirements and developing user empathy. Moreover, it provides a suite of battle-tested methods to place ourselves in the shoes of our user. The concepts and themes described in the Person-Centred Care model can be used during the understanding phase of the Design Thinking Process. The Person-Centred Care model identifies topics needing exploration and can provide guidance when creating data collection instruments. Stated 
simply, by combining these two models, we have a roadmap with both directions and destinations.
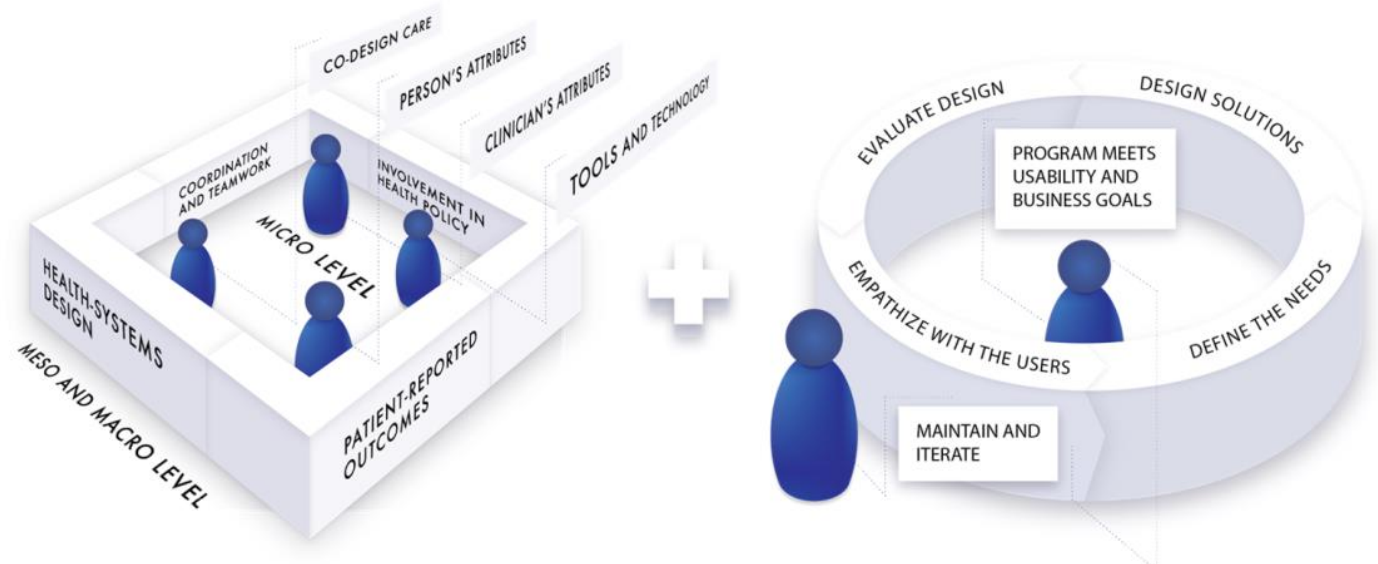

Fig. 1. Two theoretical models informing this work: the Person-Centred Care model (left) and the Design Thinking Process (right). Adapted from (Hartson \& Pyla, 2012; Santana et al., 2018; Scholl et al., 2014a).

\subsection{Journey map as a tool to foster patient empathy}

Designers often use a technique called journey mapping during the "empathize with the users" phase of product development to understand target users, clarify design requirements, and identify innovation opportunities (Banfield, Lombardo, \& Wax, 2015; Martin \& Hanington, 2012; Kumar, 2012). A JM is a visual display of a process or event, depicting how users interact with a system, interface, or organization (Rosenbaum, Otalora, \& Ramírez, 2017). Similar to workflow mapping in quality improvement, it entails collecting research on a process and documenting findings for the design team. However, workflow maps emphasize capturing all work variations and pathways, whereas JMs reflect a single "normative" process that compiles and illustrates a series of user interactions with a product on a timeline (Gibbons, 2018).

Although the exact origin of the JM is unclear, Jan Carlzon, a former chief executive officer of SAS Group, first described key concepts central to journey mapping in his book, Moment of Truth (Carlzon, 1989). The modern JM method was eventually pioneered by Bell and Zemke, authors of Managing Knock Your Socks Off Service (Bell, Zemke, \& Bush, 2013). It quickly became a popular industry instrument to understand the customer experience, identify opportunities for innovation, and influence a market. $\mathrm{JM}$ activities can be used before the launch of a product to define the anticipated user experience or following release to identify areas for improvement. Because JMs typically require background research and dialog among team members, they help create new insights and engender deep empathy for the consumers.

Journey mapping is an interdisciplinary approach used across industries; the final design of a deliverable can take a variety of forms. While many different stakeholders can co-author a JM including researchers, developers, and subject matter experts, we consider journey mapping from the perspective of a learner. In the context of education, 
journey mapping aligns well with a constructivist educational philosophy wherein the learner modifies knowledge, or constructs meaning, through active engagement or realworld problem solving (Bada \& Olusegun, 2015). There are commonalities to all JMs that we outline briefly here. A basic JM should include the following elements:

1) Persona: prior to developing a JM, the learner needs to create a persona with attributes that humanize the user. This persona provides a focus for the eventual JM.

2) Goals: the learner should clarify the objectives of the user's specific (healthcare) journey.

3) Phases: the learner should document the stages of the journey in chronological order that describe the user's touchpoints with a system. Usually, a JM has three to seven phases.

4) Actions: the learner should capture the user's corresponding actions at each phase in the journey.

5) Feelings: the learner should capture the feelings and emotional state of the user at each phase.

6) Opportunities: the JM includes a list of the potentially problematic areas (i.e., user pain points) that can be improved for a better user experience.

\subsection{Case study and design challenge}

In May 2020, 27 third-year medical students and 21 second-year physicians assistant (PA) students at OU-TU participated in a journey mapping exercise. The exercise was part of a virtual workshop on person-centred care and social determinants of health. Twelve interdisciplinary faculty from OU-TU, KU, and UVic facilitated the workshop. Our faculty boasted expertise in clinical medicine, nursing care management, medical informatics, user-interface and user-experience design, design thinking, and medical education. We also included one "near-peer" second-year PA student to assist with activity design and circulate during the workshop to provide additional instruction and feedback to learners.

The medical faculty at OU-TU routinely teach topics associated with patient care, clinical communication, and medical professionalism. For example, we incorporate topics on societal health and cultural sensitivity in lectures during the first year and we routinely observe professional conduct during clinic and bedside apprenticeships. However, outside of patient simulations and quality improvement retreats, we do not traditionally include learning activities dedicated to empathy skills or person-centred research methods (e.g., ethnography, journey mapping). Prior to the workshop, learners had not received any design training and had never been introduced to JMs, at least within the context of their education at OU-TU.

The workshop was initially intended to be a live face-to-face event. However, social distancing restrictions during the coronavirus pandemic required faculty to quickly redesign the workshop for a videoconferencing forum. Nonetheless, the workshop and the JM exercise required participants to engage in live group discussions, watch didactics, share files, and visually collaborate with their teammates using artifacts common in design studios such as adhesive notes, white boards, drawings, and photographs.

To meet workshop needs, we used several cloud-based software platforms including Google Drive, Zoom, and Mural (Google, 2012; Lauer, 2020; Zoom Video 
Communications, 2020). Google Drive is one of the most popular cloud-based file storage platforms (Nolledo, 2020). Zoom is a ubiquitous cloud-based, peer-to-peer software platform for online videoconferencing (Antonelli, 2020). Mural is a cloud-based digital workspace for visual collaboration that includes functionality to copy, drag, and position text, diagrams, virtual "adhesive notes", and digital photos.

The participants used Zoom to watch large group didactics and to hold team discussions in breakout rooms. Participants concurrently used Mural during large group and team-based activities to interact with visualization tools, assemble their JMs, and present work. The faculty could easily partition a large virtual canvas into sections for team-based work similar to asking small groups to congregate in different sections of a conference room. The benefit of this functionality was that participants and facilitators could effortlessly float between groups or take in a "bird's-eye" view of all work at once. There was no need to print, draw, or exchange emails. Because Mural was unfamiliar to most participants - including faculty - workshop organizers had to invest additional resources into training including creating and distributing "quick-reference" handouts, holding short online tutorials for learners, and conducting "dress rehearsals" with faculty.

You are a student seeing a patient in your virtual (i.e., telemedicine) longitudinal ambulatory clinic. You are seeing Ms. Diaz for the second time. She is a 45-year old female with a history of type 2 diabetes mellitus and hypertension. Spanish is her first language although she does speak English. When you saw her for the first-time last week, she had not been receiving medical care or medication refills for 6 months due to the loss of her medical insurance. Last week, she came to clinic to re-establish care and receive refills of her medications for diabetes mellitus and hypertension which included metformin 1000mg twice a day, glyburide 10mg twice a day, and nifedipine extended release 30mg once a day. She is not currently using any form of birth control. Last week, you agreed to refill her medications and ordered a Haemoglobin A1C. The lab work from last week showed her A1C to be 11.0, and she has connected with you using her smartphone to follow up on the result. Since she is on the maximum dose of her diabetes medications, you believe that starting insulin, such as once daily glargine, will be the best way to improve her A1C. You discuss with your attending and she agrees that the best plan is to begin glargine 10U once a day with continued metformin, and discontinue the glyburide.

Case adapted from: Alexander, MedEd Portal, 2016 and Ludwig et al., MedEd Portal, 2016

Fig. 2. Clinical scenario with archetypal standardized patient, clinical scenario, and design use case.

Students were furnished with a clinical scenario that included a mock patient named Ms. Diaz, a sample clinical encounter, and a systems-based design challenge (Fig. 2). The students were divided into ten teams; each team included three medical students, one or two physicians assistant students, and a faculty mentor. We asked teams to create a persona for Ms. Diaz in Mural based on the archetype provided. The purpose of the persona was to help students visualize Ms. Diaz and identify with her as an individual with values and agency rather than a patient with a collection of medical problems. The persona needed to include the following information: Ms. Diaz's full name, home 
address, a portrait, images or descriptions of things she loves and hates, types of transportation she regularly uses, and types of foods she usually eats.

The facilitators introduced the purpose and format of a JM and provided learners with a sample JM template they could use in Mural during the exercise (Fig. 3). One template was posted on the Mural board for each team; team members were able to annotate the template and see peer work evolve in real time. We apportioned approximately 20 minutes for faculty to describe the persona task and allow learner teams to generate personas. We then apportioned approximately 45 minutes for faculty to describe the journey mapping activity, allow learners to create a journey map, and provide a brief report-out in the large group. The top of the JM included a brief description of the scenario and a space for students to list Ms. Diaz's (1) goals and expectations for the clinical visit. The remainder of the JM template was organized into a grid that included the following rows (i.e., sections): (2) phase and doing; (3) thinking; (4) feeling; (5) opportunity; and (6) recommendations.

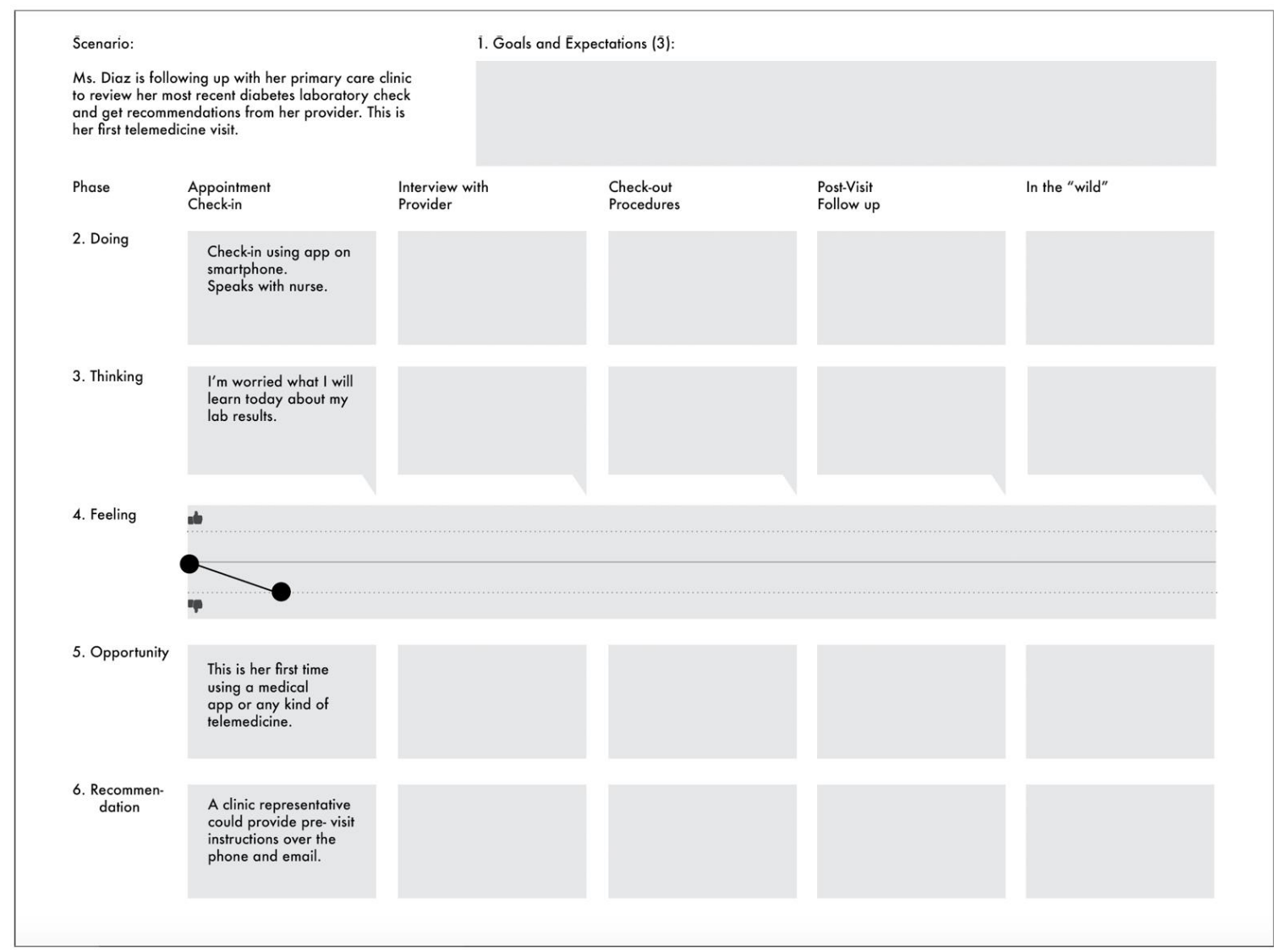

Fig. 3. Journey map template furnished to students for the design exercise

The scenario included the following language, "Ms. Diaz is following up with her primary care clinic to review her most recent diabetes laboratory check and get recommendations from her provider. This is her first telemedicine visit." The learners were required to complete the goals and expectations section. We outlined the five phases we wanted our students to explore including the appointment check-in, provider 
interview, check-out, post-visit follow up, and health maintenance (denoted on the figure as "in the wild"). The intent of the post-visit maintenance step was to help students visualize and describe the background context of Ms. Diaz's daily life. For each box in the grid, we asked students to provide details illustrating the phase and potential activities. We filled out the first phase of the template as an example of the activity expectations. In accordance with JM conventions, we asked each team to draw a line graph reflecting the patient's emotional state throughout the process rather than entering narrative text.

\subsection{Journey map analysis}

Workshop faculty members conducted a qualitative analysis of each JM and coded each written statement, quote, or concept listed on the maps. We applied a First Cycle (i.e., "first-pass") coding approach using structural codes that sorted all findings into one of two a priori conceptual categories: (1) medical concept or attribute; and (2) socio-cultural concept or attribute (Saldaña, 2015). We chose this approach for several reasons. First, this strategy provided a rapid way to quickly analyse student deliverables at the pace of operations. Second, these categories enabled the faculty to determine whether the JM format guided learners to explore contextual, socio-cultural, or societal determinants of health affecting the patient experience or health outcomes. Third, First Cycle coding processes are intended to be a simple and direct way to inventory a corpus of data. It is well suited to piloting a new study design, whereas Second Cycle coding methods are more complex and are applied iteratively to synthesize, abstract, or further conceptualize data during theory building (Saldaña, 2015).

We coded all data at the statement level (i.e., the sentence or phrase entered into a panel in the JM). We coded any clinical statements discussing illnesses, symptoms, medical records, diagnostic tests, and treatments as "medical". For example, we coded the statement, "Wants to know about risks and benefits of medication," as medical. We coded any statements describing sociocultural attributes, environmental issues, or societal problems as "socio-cultural". Socio-cultural statements included topics of lifestyle, finances, family relationships, dietary habits, and living conditions. For example, we coded the statement, "Not increase [children's] financial burden" as socio-cultural.

An application for this educational work was submitted to our Institutional Review Board (IRB) for review. The IRB defined the work as "quality improvement" and exempt from further oversight.

\section{Results}

The 10 breakout groups produced $10 \mathrm{JMs}$; Fig. 4. shows an example learner-created JM. Learners were able to use the JM to depict steps in a healthcare encounter as well as details of Ms. Diaz' everyday life. By visualizing Ms. Diaz's experience with the virtual clinic and including thoughts and feelings informed by her background and lifestyle, the learners were able to document potential pain points and suggestions to improve the experience. For example, in the "recommendations" section, learners identified potential resources and strategies to address Ms. Diaz's language barriers, lifestyle choices, and follow communications with the clinic. 


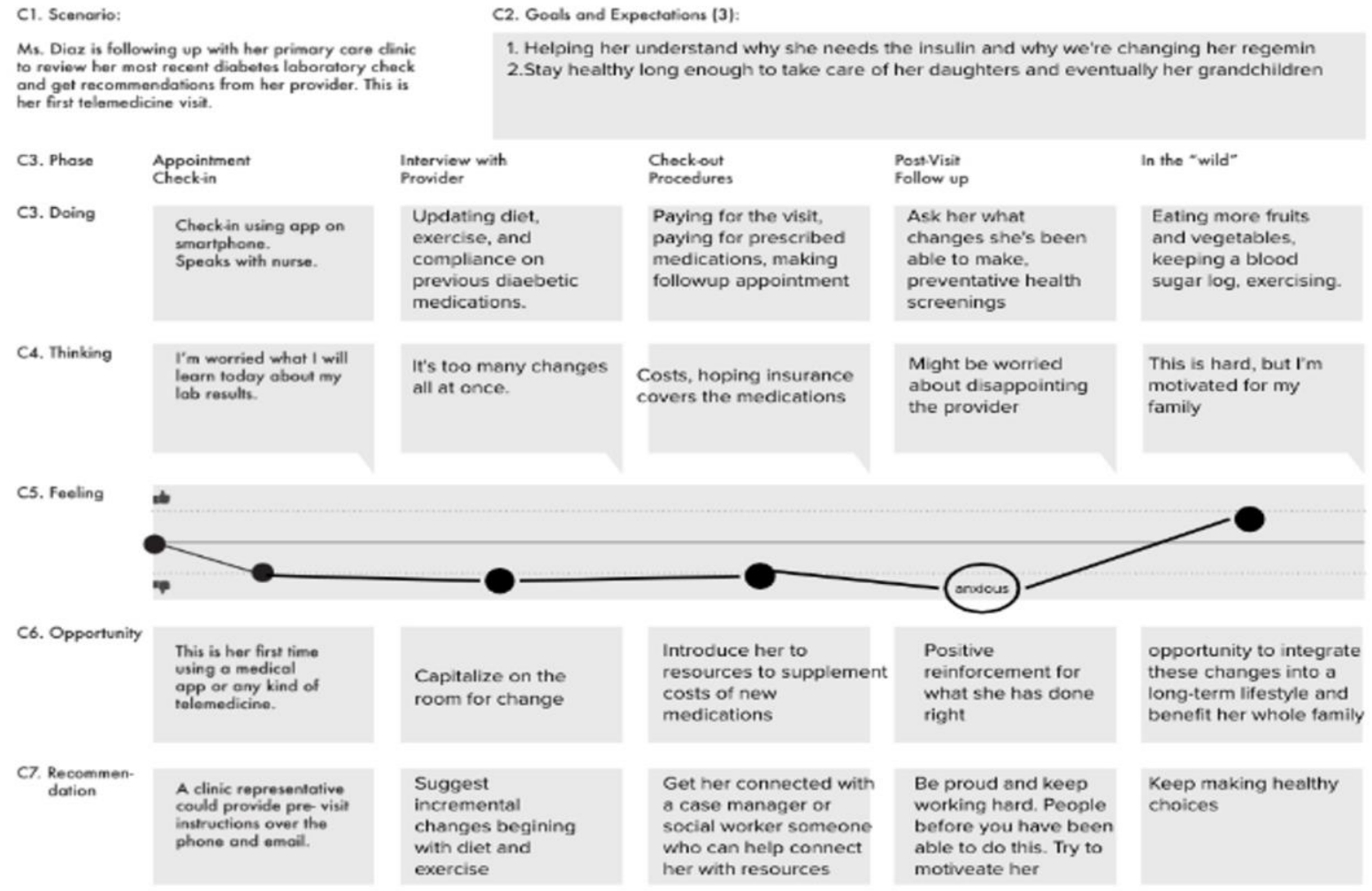

Fig. 4. Sample JM generated by the learner team coached by a faculty member

Table 2 shows the number of unique themes or ideas captured in the JMs and organized by JM section and our thematic categories (i.e., medical and socio-cultural). For example, we identified 28 unique themes and ideas for the "Goals and expectations" section across all $10 \mathrm{JMs}$. Nineteen of the themes and ideas addressed a medical concept, whereas nine addressed a sociocultural concept.

Table 2

Counts and percentages of unique concepts documented in learner JMs and organized according to our a priori categories (i.e., medical and socio-cultural). The unit of analysis was the statement level. Statements that included concepts from both categories were counted twice (i.e., once for each category).

\begin{tabular}{lccc}
\hline Section & Total Responses & Medical (\% Section Total) & Socio-Cultural (\% Section Total) \\
\hline Goals and Expectations & 28 & $19(67.9)$ & $9(32.1)$ \\
Doing & 42 & $22(52.4)$ & $20(47.6)$ \\
Thinking & 36 & $18(50.0)$ & $18(50.0)$ \\
Opportunity & 20 & $14(70.0)$ & $6(30.0)$ \\
Recommendation & 17 & $6(35.3)$ & $11(64.7)$ \\
Total & 143 & $79(55.2)$ & $64(44.8)$ \\
\hline
\end{tabular}


Overall, medical responses (55\%) mainly described Ms. Diaz's concerns about diabetes management, lab results, and medication administration, including transitioning from oral medications to insulin therapy (Table 3). Medical responses also included concerns about using telemedicine, technology literacy, and functional health literacy. The socio-cultural responses (45\%) reflected concerns about family relationships, dietary choices and habits, language, cultural norms, and access to infrastructure and information technology such as wireless internet.

\section{Table 3}

Representative statements abstracted from JM and sorted according to JM sections and qualitative codes

\begin{tabular}{|c|c|c|}
\hline & Medical & Socio-Cultural \\
\hline Definitions & $\begin{array}{l}\text { Statements discussing illnesses, symptoms, } \\
\text { medical records, diagnostic tests, and treatments }\end{array}$ & $\begin{array}{l}\text { Sociocultural attributes, environmental issues, } \\
\text { or societal problems }\end{array}$ \\
\hline \multicolumn{3}{|l|}{ Sections } \\
\hline Goals and expectations & $\begin{array}{l}\text { - Wants to know how her well she is managing } \\
\text { her diabetes } \\
\text { - } \quad \text { Risks and benefits of medication }\end{array}$ & $\begin{array}{l}\text { - } \quad \text { Not increase financial burden } \\
\text { - } \quad \text { Stay healthy...to take care of family }\end{array}$ \\
\hline Doing & $\begin{array}{l}\text { - } \quad \text { She is receiving her lab results } \\
\text { - } \quad \text { Listening to provider }\end{array}$ & $\begin{array}{l}\text { - } \quad \text { Taking care of children } \\
\text { - } \quad \text { Using public WiFi could be a pain point }\end{array}$ \\
\hline Thinking & $\begin{array}{l}\text { - What does A1C really mean? } \\
\text { - I don't understand injections? Why not another } \\
\text { pill? }\end{array}$ & $\begin{array}{l}\text { - My kids don't like the food they are } \\
\text { talking about } \\
\text { - I need to get home to make dinner and } \\
\text { check on the kids }\end{array}$ \\
\hline Opportunity & $\begin{array}{l}\text { - Diabetes education, ask about her worries } \\
\text { - } \quad \text { Learn how to use telemedicine }\end{array}$ & $\begin{array}{l}\text { - No education in her native language } \\
\text { - Opportunity to integrate these changes... } \\
\text { and benefit the whole family }\end{array}$ \\
\hline \multirow[t]{2}{*}{ Recommendation } & $\begin{array}{l}\text { - Create an infographic handout that details } \\
\text { everything important about DM and insulin use } \\
\text { - }[\text { Teach] how to use telemedicine }\end{array}$ & $\begin{array}{l}\text { - Get her connected with a case manager or } \\
\text { social worker } \\
\text { - }[\text { Use] Facetime, Marco Polo, and Spruce } \\
\text { apps...for communicating }\end{array}$ \\
\hline & $\begin{array}{l}\text { Interview } \\
\text { with Provider }\end{array}$ & $\begin{array}{l}\text { Post-Visit } \\
\text { Follow up }\end{array}$ \\
\hline 4. Feeling & מח & \\
\hline
\end{tabular}

Fig. 5. Combined responses for the "feeling" section of the JM

The learners graphed the change in Ms. Diaz's feelings throughout the healthcare journey (Fig. 5). Each of the 10 teams tried to graph Ms. Diaz's emotional state. 
However, some technical issues with Mural (i.e., internet and server bandwidth limitations) prohibited all teams from turning in real-time results. Therefore, we only provide graphs from three teams. The overall flow across student graphs showed a positive trend. However, there appeared to be the widest discordance in perceived emotional state during the Post-visit Follow Up phase.

\section{Discussion}

\subsection{Principal findings}

Our findings indicate that health professional students were able to learn about and create JMs to analyse healthcare delivery processes, technologies, or other innovations. By mapping out a normative flow, examining user experience in multiple dimensions, and reflecting upon the user's context, learners were able to identify potential failure modes at healthcare touchpoints as well as a range of health-related social needs that might be otherwise overlooked. Our use-case and design challenge offered a practical strategy for teaching about person-centred care and the social determinants of health. The JMs for Ms. Diaz helped identify important barriers and opportunities to improve tele-medical care for vulnerable, underserved, or marginalized patient populations.

In an actual design project, the design team would conduct background research on the target user to test and validate assumptions. This might include direct observations, surveys, interviews, literature reviews, and artifact analysis. We believe that providing learners with opportunities to conduct their own fieldwork would increase the quality of the learning experience and the development of patient-care and healthsystems competencies. However, this was not practically feasible given our resource and curriculum constraints. This fact notwithstanding, JM provided students with a practical tool for visualizing the user's perspective, challenging their own assumptions, highlighting knowledge gaps, and laying the groundwork for future design activities. The students were able to rapidly move past documentation of physical activities and business touch-points to explore the thoughts, feelings, and goals that contribute to the overall customer experience. We believe that combining this technique with simulation training, direct-patient exposure in traditional clerkships, and community outreach projects can expand their knowledge of user-centred design, build empathy for their patients, and prepare students to identify and ideate solutions to societal and socio-technical problems adversely affecting community health.

Finally, we were able to demonstrate that our virtual workshop format, using a combination of cloud-based software, offered a feasible approach for engaging students in an active learning environment. Online learning and virtual classrooms significantly change the educational dynamic and can challenge educators to effectively engage students in a dialog. However, we believe this pilot highlighted several unique advantages. We were able to complete nearly all of the large and small group exercises initially planned for a live face-to-face workshop. The videoconferencing platform enabled us to connect a large group over considerable geographic distance, including interdisciplinary educators with specialized expertise from around North America. Also, Mural's collaborative environment provided a robust, scalable, and well-equipped virtual design studio that might otherwise be cost prohibitive to replicate in a live format. Conceivably, this virtual workshop approach could be used periodically in a longitudinal curriculum to teach each phase of the design lifecycle. 


\subsection{Implications of findings}

We believe the JM is an underused instructional technique in medical education that can be applied to a broad range of topics in the competency domains of medical professionalism, inter-professional communication, patient care and person-centred care, and systems-based practice (Bearnot \& Mitton, 2020; Giambattista \& Zolotova, 2019; Halvorsrud, Lillegaard, Røhne, \& Jensen, 2019; Kelly et al., 2016; McCarthy et al., 2020; Westbrook, Coiera, Gosling, \& Braithwaite, 2007). Journey maps, personas, and related design thinking methods used to understand people provide a ready-made set of active learning tools to internalize the values and attitudes necessary to provide compassionate, altruistic, and personalized care (McCarthy et al., 2020). JMs can be integrated into lesson plans addressing empathy, social determinants of health, cultural sensitivity, implicit bias, person-centred care, and evidence-based quality improvement. These tools also help to integrate the cognitive learning (i.e., knowledge) associated with systemsbased content with the psychomotor learning (i.e., skills and abilities) needed to develop, deploy, and test solutions.

Our JM emphasized one phase of the design thinking process. The concepts and skills associated with the design thinking process complement related material covered in systems-based practice, including patient safety and total quality management. The virtual workshop format can be leveraged as a constructivist educational strategy to integrate experiential learning from patient care with the theoretical models and concepts introduced with evidence-based design, medical informatics, and health-systems science. The entire design thinking process could be introduced through a longitudinal curriculum to augment instruction on quality improvement science and help students master skills needed as future healthcare leaders. One practical example could be to combine this method with didactic content provided by the Institute for Healthcare Improvement's Open School and coach interdisciplinary teams of students through a year-long clinicbased quality improvement initiative (Ryan Miller, Tessa Winterton, \& Hoffman, 2014).

The participants' statements and insights from the JM exercise highlight the importance of engaging patients in the participatory design of telehealth technologies. Patient information technology literacy, functional health literacy, medical health status, and sociocultural context can all act as mediating variables upon access-to-care, patient engagement, health outcomes, and patient defined outcomes. Based upon learner ideation during the JM exercise, we see the potential to proactively collaborate with healthcare professionals and other stakeholders throughout the design lifecycle to improve the usability of telemedicine platforms.

\subsection{Strengths and limitations}

The work presented in this manuscript has several notable strengths. First, to our knowledge, this is the first reported use of journey mapping in medical education to teach educational program objectives. Most of the published literature describes healthcare professionals, designers and systems engineers using JMs to solve health systems problems (Bearnot \& Mitton, 2020; McCarthy et al., 2020). Second, we were able to pilot our mapping exercise with a cross-section of professionals. We leveraged talents of an interdisciplinary team boasting expertise in clinical medicine, medical informatics, evidence-based design, design thinking, user-interface and user-experience design, and health systems engineering. Third, we used several complementary theoretical frameworks to inform our design and schematize our educational activities. Finally, the methods should translate readily to other health professional training programs; we 
provided sufficient details about the use-case, materials, and JM analysis strategy to replicate this exercise.

There are also several limitations that deserve mention. First, our team was provided a protected time to conduct the JM exercise. Considering the heavy workload of medical students with clinical schedules, it is challenging to find time for this new curricular activity and may require months of advanced planning. Second, a successful journey mapping training requires multiple instructors that have cross-training in healthcare and a systems-science or design specialty. For example, two of our faculty members had board certification in a medical specialty and in medical informatics. We also had one faculty with expertise in design thinking and with extensive experience in designing for healthcare. Third, this work represents a pilot with a small pool of learners. Ideally, we need to repeat this workshop with a larger sample size and with other types of learners such as students in social work, nursing, and health administration. Fourth, our qualitative analysis of JMs only included a preliminary First Cycle coding analysis to rapidly inventory learner observations. A more robust qualitative analysis would apply more codes derived from our theoretical framework, code a larger corpus of data, and include multiple validation steps with kappa calculations. Finally, we mapped our workshop learning objectives to competencies for a single allopathic medical program. Ideally, we would need to cross-walk competencies from multiple health professional programs to develop a meta-set of educational program objectives and then develop the formative and summative measures to assess knowledge, attitudes, and skills in an externally validated way.

JMs also have limitations. Its formality can artificially reinforce a linear understanding of the user workflow or experience even when the actual process is organic or multidimensional (Kaplan, 2016). Journey maps can place disproportionate focus upon the business touch points rather than the users' actual experience (Rosner, 2020). Finally, a JM does not prioritize touch points for action even when all findings may not be equally important (Rosenbaum et al., 2017). To overcome these limitations, we recommend the following steps: (1) combine JM with other design thinking exercises such as persona development and empathy mapping; (2) expand the scope of the 'journey' to include the patient's entire day; and (3) roughly draft the entire JM as a large-group activity, discuss key insights, and then assign specific parts of the journey to each small team for additional research and refinement.

\subsection{Next steps}

Our implications and limitations provide considerable insight into the next logical steps to continue developing this work. We anticipate building a larger set of formative and summative educational metrics to measure (1) the learner-reported quality of the educational program and (2) the effect upon learner development and our ability to meet educational program objectives. Notionally, future measures could include continuing medical education-style program evaluation surveys, distribution of the Net Promoter Score or other self-reported usability and satisfaction survey instrument, and longitudinal performance measurement through the use of high-fidelity simulations or partnerships with clinical clerkships.

We also believe there is an opportunity to work with qualitative researchers from other fields (e.g., design education, health services research, informatics) to develop new coding schemas based upon other theoretical frameworks and add a Second Cycle coding strategy to synthesize and conceptualize data. For example, we could use JM and similar 
design artifacts to more granularly explore concepts such as learner concept mastery, social needs identification, patient health literacy, population health disparities, health systems gaps, health information technology usability, and best-practice implementation barriers. Conversely, we could work with experts from the design, systems-engineering, and software development industries to create validated qualitative analysis techniques to better measure the quality, accuracy, completeness, and value of JM within the context of analyzing a health system.

\subsection{Conclusions}

This manuscript described a novel pilot of JM with health professional students to address curriculum competency domains and educational program objectives. There are many benefits associated with JM development. First, it allows learners to build empathy toward their users by understanding how users, patients, experience a telemedicine product. Second, JMs illustrate the product's current performance to identify target users' needs. Third, journey mapping creates new insights by visualizing the users' motivations, actions, and emotions (Bosio, 2019).

While JM has been widely utilized in the design and marketing industries as part of a design thinking paradigm, it has been underutilized in healthcare to grapple with issues of personalized care and health-related social needs. Given the rapidly growing digital product market and emergence of an eHealth ecosystem, healthcare professionals must possess an understanding of their patient's needs and an ability to perceive design problems from their users' perspectives. We believe journey mapping provides a method to increase understanding of the patient experience and identify how to meaningfully engage patients throughout a health-systems design and improvement lifecycle. Stated simply, the participatory design methods inherent in the design thinking and peoplecentred design are ideally suited to explore themes in the Person-Centred Care Model and generate a rich, multidimensional understanding of the healthcare consumer, their context of care, and the social determinants influencing health outcomes.

\section{Author Statement}

The authors declare that they have no conflict of interest.

\section{Acknowledgements}

This research was supported by the School of Architecture and Design, University of Kansas, and School of Community Medicine, University of Oklahoma-Tulsa. The authors would thank all the faculty members and medical and PA students who participated the design thinking workshop.

\section{ORCID}

Hannah Park (10 https://orcid.org/0000-0002-6811-4245

Helen Monkman (i) https://orcid.org/0000-0003-0772-9075

Allison Wenger (ib) https://orcid.org/0000-0002-5228-2447

Blake Lesselroth (iD https://orcid.org/0000-0001-6170-7964 


\section{References}

Antonelli, W. (2020). What is Zoom? A comprehensive guide to the wildly populatr video-chatting service for computers and smartphones. Retrieved from https://www.businessinsider.com/what-is-zoom-guide

Bada, S. O., \& Olusegun, S. (2015). Constructivism learning theory: A paradigm for teaching and learning. IOSR Journal of Research \& Method in Education, 5(6), 66-70.

Banfield, R., Lombardo, C. T., \& Wax, T. (2015). Design sprint: A practical guidebook for building great digital products. Sebastopol, Canada: O'Reilly Media, Inc.

Bearnot, B., \& Mitton, J. A. (2020). "You're always jumping through hoops": Journey mapping the care experiences of individuals with opioid use disorder-associated endocarditis. Journal of Addiction Medicine, 14(6), 494-501.

Bechtel, C., \& Ness, D. L. (2010). If you build it, will they come? Designing truly patient-centred health care. Health Affairs, 29(5), 914-920.

Bell, C., Zemke, R., \& Bush, J. (2013). Managing knock your socks off service. New York, NY: Amacom.

Berwick, D. M., Nolan, T. W., \& Whittington, J. (2008). The triple aim: Care, health, and cost. Health Affairs, 27(3), 759-769.

Bosio, B. (2019). Cae study: Student journey mapping. Retrieved from https://www.smaply.com/blog/case-study-students-journey-map

Carlzon, J. (1989). Moments of truth, reprint ed. New York, NY: HarperCollins,

Constand, M. K., MacDermid, J. C., Dal Bello-Haas, V., \& Law, M. (2014). Scoping review of patient-centred care approaches in healthcare. BMC health services research, 14: 271.

Corrigan, J. M. (2005). Crossing the quality chasm. Building a better delivery system. Washington, DC: National Academies Press Publications.

Davis, K., Schoen, C., Schoenbaum, S. C., Audet, A.-M. J., Doty, M. M., \& Tenney, K. (2004). Mirror, mirror on the wall: Looking at the quality of American health care through the patient's lens. The Commonwealth Fund. Retrieved from https://collections.nlm.nih.gov/master/borndig/101223497/Mirror\%20mirror\%20on\% 20the\%20wall\%20looking\%20at\%20quality.pdf

Davis, K., Schoenbaum, S. C., \& Audet, A.-M. (2005). A 2020 vision of patient-centred primary care. Journal of General Internal Medicine, 20(10), 953-957.

Englander, R., Cameron, T., Ballard, A. J., Dodge, J., Bull, J., \& Aschenbrener, C. A. (2013). Toward a common taxonomy of competency domains for the health professions and competencies for physicians. Academic Medicine, 88(8), 1088-1094.

Englander, R., Frank, J. R., Carraccio, C., Sherbino, J., Ross, S., Snell, L., \& Collaborators, I. (2017). Toward a shared language for competency-based medical education. Medical Teacher, 39(6), 582-587.

Giambattista, A., \& Zolotova, M. (2019). Design to care: Education experiences to design local healthcare services. In Proceedings of the Cumulus Conference (pp. 509-525). Rovaniemi. Finland.

Gibbons, S. (2018, December 9). Journey mapping 101. Nielsen Norman Group. Retrieved from https://www.nngroup.com/articles/journey-mapping-101/

Google. (2012). Google Drive. Retrieved from https://drive.google.com/drive/my-drive

Halton, C., \& Cartwright, T. (2018). Walking in a patient's shoes: An evaluation study of immersive learning using a digital training intervention. Frontiers in Psychology, 9: 2124. doi: 10.3389/fpsyg.2018.02124

Halvorsrud, R., Lillegaard, A. L., Røhne, M., \& Jensen, A. M. (2019). Managing complex patient journeys in healthcare. In M. A. Pfannstiel \& C. Rasche (Eds.), Service Design and Service Thinking in Healthcare and Hospital Management (pp. 329-346). Springer. 
Hartson, R., \& Pyla, P. S. (2012). The UX book: Process and guidelines for ensuring a quality user experience. Elsevier.

Kaplan, K. (2016). Journey mapping in real life: A survey of UX practitioners. Retrieved from https://www.nngroup.com/articles/journey-mapping-ux-practitioners/

Kelly, J., Wilden, C., Chamney, M., Martin, G., Herman, K., \& Russell, C. (2016). Improving cultural and clinical competency and safety of renal nurse education. Renal Society of Australasia Journal, 12(3), 106-112.

Kumar, V. (2012). 101 design methods: A structured approach for driving innovation in your organization. John Wiley \& Sons.

Lauer, S. (2020). Getting started with remote collaboration. Retrieved from https://blog.powertofly.com/mural-remote-work-resiliency-plan-2645946251.html

Lesselroth, B., Monkman, H., Adams, K., Wood, S., Corbett, A., Homco, J., ... Kushniruk, A. W. (2020). User experience theories, models, and frameworks: A focused review of the healthcare literature. Studies in Health Technology and Informatics, 270, 1076-1080.

Martin, B., \& Hanington, B. (2012). Universal methods of design: 100 ways to research complex problems, develop innovative ideas, and design effective solutions. Beverly, MA: Rockport Publishers.

McCarthy, S., O'Raghallaigh, P., Woodworth, S., Lim, Y. Y., Kenny, L. C., \& Adam, F. (2020). Embedding the pillars of quality in health information technology solutions using "Integrated patient journey mapping" (IPJM): Case study. JMIR Human Factors, 7(3): e17416.

McWhinney, I. (1989). The need for a transformed clinical method. In M. Stewart \& D. Roter (Eds.), Communicating with Medical Patients (pp. 25-42). London, UK: Sage.

Mead, N., \& Bower, P. (2000). Patient-centredness: A conceptual framework and review of the empirical literature. Social Science \& Medicine, 51(7), 1087-1110.

Nolledo, M. (2020). Google Drive is a modern-day hard drive. Tech Reference. Retrieved from https://www.businessinsider.com/what-is-google-drive-guide

Park, H., Lesselroth, B., Cardona Giraldo, M. J., Chiao, D., Jerome, K., Perez, A. E. P., \& Thomas, S. (2021). Design thinking X medical education: Empowering empathy for patient-centred care. Paper presented at the 2021 College Art Assocation (CAA) Annual Conference.

Rosenbaum, M. S., Otalora, M. L., \& Ramírez, G. C. (2017). How to create a realistic customer journey map. Business Horizons, 60(1), 143-150.

Rosner, C. (2020). The evolution of customer journey mapping. Retrieved from https://www.ttec.com/articles/evolution-customer-journey-mapping

Ryan Miller, M., Tessa Winterton, M., \& Hoffman, W. W. (2014). Building a whole new mind: An interprofessional experience in patient safety and quality improvement education using the IHI Open School. South Dakota Medicine, 67, 17-19, 21-23.

Saldaña, J. (2015). The coding manual for qualitative researchers. Sage.

Santana, M. J., Manalili, K., Jolley, R. J., Zelinsky, S., Quan, H., \& Lu, M. (2018). How to practice person-centred care: A conceptual framework. Health Expectations, 21(2), 429-440.

Scholl, I., Zill, J. M., Härter, M., \& Dirmaier, J. (2014a). How do health services researchers understand the concept of patient-centredness? Results from an expert survey. Patient Prefer Adherence, 8, 1153-1160.

Scholl, I., Zill, J. M., Härter, M., \& Dirmaier, J. (2014b). An integrative model of patientcentredness-A systematic review and concept analysis. PloS One, 9: e107828.

Skochelak, S. E., Hawkins, R. E., Lawson, L. E., Starr, S. R., Borkan, J., \& Gonzalo, J. D. (2016). Health systems science e-book. Philadelphia, PA: Elsevier.

Soegaard, M. (2018). The basics of user experience design. Interaction Design Foundation. 
Tanenbaum, S. J. (2015). What is patient-centred care? A typology of models and missions. Health Care Analysis, 23(3), 272-287.

Tjendra, J. (2014). The origins of design thinking. Wired Magazine. Retrieved from https://www.wired.com/insights/2014/04/origins-design-thinking/

Westbrook, J. I., Coiera, E. W., Gosling, A. S., \& Braithwaite, J. (2007). Critical incidents and journey mapping as techniques to evaluate the impact of online evidence retrieval systems on health care delivery and patient outcomes. International Journal of Medical Informatics, 76(2/3), 234-245.

Zoom Video Communications. (2020). Zoom Videoconferencing Software. Retrieved from https://www.zoom.us/ 